\title{
Trends in spring snowpack over a half-century of climate warming in California, USA
}

\author{
Ian M. HOWAT, Slawek TULACZYK \\ Department of Earth Sciences, University of California, 1156 High Street, Santa Cruz, CA 95064, USA \\ E-mail: ihowat@es.ucsc.edu
}

\begin{abstract}
Linear trends in 1 April snow water equivalent (SWE) in California, USA, are determined from a dense network of observations over the period 1950-2002. These trends are compared to concurrent time series of precipitation and temperature and Pacific Ocean climate indices. We find increased winter temperatures have accompanied both decreasing and increasing SWE trends, resulting in a weak overall negative trend in spring SWE. The spatial distribution of SWE trend is dependent on both latitude and elevation. Increases in both precipitation and temperature have led to increases in SWE at high elevations in southern Sierra Nevada and decreases at lower elevations. Increased temperature and decreased precipitation are associated with SWE loss in northern California. Trends in SWE can partially be attributed to shifts in Pacific Ocean climate indices.
\end{abstract}

\section{INTRODUCTION}

In arid and semi-arid regions, the loss of alpine snowpack represents one of the most severe potential impacts of climate warming, threatening the reduction of a critical dryseason water source. In the western United States, where up to $70 \%$ of the annual river discharge is supplied from snowmelt (Serreze and others, 1999), recent observations of warming winter temperatures, earlier spring onsets and shrinking seasonal snow cover have heightened concern over the effect of future climate change on alpine snowpack (Dettinger and Cayan, 1995; Brown, 2000; Cayan and others, 2001). In the water-strained state of California, regional climate models estimate up to a $60 \%$ reduction in spring snowpack in the next 100 years, due to a regional, greenhouse-driven warming of up to $3^{\circ} \mathrm{C}$ (Kim, 2001; Knowles and Cayan, 2002; Snyder and others, 2002).

California has become a focal point for monitoring the impact of climate change on hydrology. The general concern is that near-future climate warming will further stress the already scarce water resources of the state's rapidly growing population and large economy (Snyder and others, 2002; Miller and others, 2003). The role of alpine snowpack as an essential seasonal water reservoir has led California to maintain the highest-density network of snowcourse stations in the United States (265 currently active stations) (M. Roos, http://cdec.water.ca.gov/snow/meeting/ CCSS_2003_Meeting/Calif_Coop_Snow_Program.pdf). Over 200 of these stations have been maintained for the last halfcentury, presenting a unique opportunity to examine spatial and temporal trends in seasonal snowpack at a relatively high spatial resolution.

In this study, we analyze 52 years of 1 April snow water equivalent (SWE) measurements from the Sierra Nevada and southern Cascade mountains of California (Fig. 1). Since this region receives most of its snowfall between December and April, 1 April SWE approximates the net balance between total annual snowfall and winter season melt, termed the winter balance (Bohr and Aguado, 2001). We determine the temporal linear trends in 1 April SWE, their spatial variability, and their statistical correlation to regional and Pacific-scale climate variability over the past half-century. This analysis is aimed at improving our understanding of the climate forcing responsible for recent variations in California's SWE.

\section{DATA AND METHODS}

\subsection{Snow-course data}

This analysis uses SWE measurements from snow courses maintained by the California Cooperative Snow Survey of the California Department of Water Resources. A review of the data collection and verification program is provided by M. Roos (http://cdec.water.ca.gov/snow/meeting/ CCSS_2003_Meeting/Calif_Coop_Snow_Program.pdf). We excluded those time series that were missing more than a total of five years of observations or more than two consecutive years. These requirements yielded a total of 201 station time series beginning in the year 1950. Throughout this paper, SWE refers to 1 April SWE measurements.

\subsection{Climate data}

We use monthly mean temperature and total monthly precipitation datasets for the period 1950-2002 from the US National Climate Data Center (NCDC). Where available, we utilize climate data that have undergone extensive quality control as part of the United States Historical Climate Network (USHCN) (Karl and others, 1990). However, due to the sparse distribution of USHCN corrected stations in mountainous parts of California, this dataset is supplemented with all other available NCDC distributed data. For further quality control, the analysis described in this paper was performed once using only the USHCN corrected dataset, and a second time with the full NCDC dataset. There was no difference between the general results of the two analyses, apart from a greater correlation between SWE and climate variables when all the NCDC data were used. As in the case of the SWE data, we retained only those time series which were not missing two consecutive years of measurements or five years' total. The precipitation and temperature anomalies were averaged for December-April of each year. In California, as in other areas of the western United States, winter temperature and precipitation are largely uncorrelated (average absolute correlation is 0.12). Following an analysis of Pacific Northwest SWE by Mote 


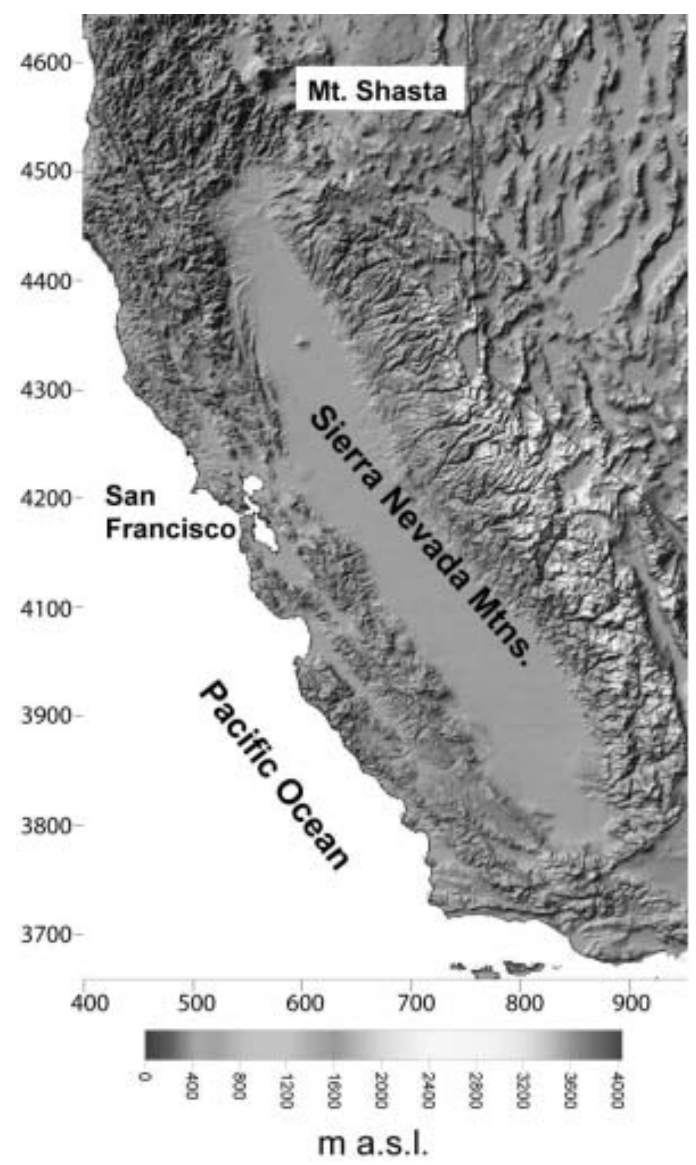

Fig. 1. Shaded relief map of the study region. Coordinates in Universal Transverse Mercator kilometers.

(2003a), SWE time series were correlated to the mean climate anomalies of the five nearest available climate stations, with separation distance averaging $31 \mathrm{~km}$ and no greater than $72 \mathrm{~km}$. These distances are comparable to the differences reported in the Mote (2003a) study. This averaging scheme is adopted to limit the sensitivity of our analysis to factors local to individual climate stations (e.g. wind patterns, changes in foliage, measurement error). Snow-course stations averaged $520 \mathrm{~m}$ higher in elevation than the nearest climate station. A description of the limitations and uncertainties in correlating lower-elevation climate measurements to higher-elevation SWE is given by Mote (2003a). Due to these limitations, all interpretations of results are restricted to regional-scale patterns of correlations and trends.

For correlation between temporal patterns of SWE and Pacific climate modes, time series for winter means of the Niño-3 and Pacific Decadal Oscillation (PDO) indices were calculated from monthly values obtained from the Joint Institute for the Study of Atmosphere and Ocean/University of Washington website (http://tao.atmos.washington.edu/ data_sets/).

\subsection{Data analysis}

Trends in each SWE and climate time series are determined from the slope of the linear regression line through the data points over the 52 year period. Trends given in per cent are the total change relative to the $y$-intercept of the regression line. Following the methodology of Mote (2003a), we use multiple linear regression to determine the dependence of the variation and trend of each SWE time series, $S(t)$, on corresponding reference climate time series of temperature $T(t)$ and precipitation $P(t)$. The resulting regression coefficients, $a_{t}$ and $a_{p}$, for temperature and precipitation respectively, yield the component of the trends in SWE $\langle S\rangle$ that can be explained by trends in temperature $\langle T\rangle$ and precipitation $\langle P\rangle$ through the relation:

$$
\begin{aligned}
\langle S\rangle_{\mathrm{t}} & =a_{\mathrm{t}}\langle T\rangle \\
\langle S\rangle_{\mathrm{p}} & =a_{\mathrm{p}}\langle P\rangle
\end{aligned}
$$

\section{RESULTS}

\subsection{Trends in SWE}

California's SWE has decreased by a station-wide average of $1.2 \%$ over the past 52 years. However, this value is the mean of more significant decreases and increases over the region. The spatial distribution of SWE trend, in both $\mathrm{cm} \mathrm{a}^{-1}$ and per cent, is shown in Figure 2. The pattern of SWE trends shows a dependency on both latitude and elevation. Selecting $2300 \mathrm{~m}$ as the approximate elevation of zero trend in Figure 2, we find that stations below $2300 \mathrm{~m}$ elevation have lost, on average, $13 \%$ SWE while higher-altitude stations have gained $12 \%$. This spatial distinction can also be made between the northern and southern halves of the study area, averaging $-15 \%$ and $10 \%$ respectively.

Since station elevation varies strongly with latitude, reflecting the altitude distribution of California, we cannot uniquely conclude whether the observed north-south contrast in SWE trend is dependent on elevation, latitude or both. The correlation coefficients between relative SWE trend and station latitude and elevation are -0.51 and 0.56 respectively. To further constrain the cause(s) of this spatial dependency, we turn to correlations with climate-station time series.

\subsection{Correlation with trends in regional climate}

Numerous studies have cited increases in winter precipitation and temperatures in California over the past halfcentury (Groisman and others, 2001; Lund and others, 2001). Change has been greatest in the southeastern section of the study area, where temperature has increased $>3{ }^{\circ} \mathrm{C}$ and total winter precipitation has doubled at multiple stations. In agreement with observed trends in the Pacific Northwest, winter precipitation has decreased in extreme northwestern California (Mote, 2003b).

The correlation coefficient between winter precipitation and SWE averages 0.72 and is as high as 0.91 . This positive correlation is significant at the 0.05 level for nearly every SWE time series. The correlation is strongest in the southern Sierra Nevada and in the northwestern coastal mountains. Mean winter temperature is significantly anticorrelated with low- and mid-elevation SWE time series in the central Sierra Nevada and the northwest corner, with a correlation coefficient ranging down to -0.55 and averaging -0.29 across all of the study area. Consistent with observations from the Rocky Mountains, we observe a low correlation between mean winter temperature and SWE at high elevations because these stations are above the freezing altitude for much of the winter and would be insensitive to temperature variations (Mote, 2003a).

Employing the multiple regression analysis outlined in section 2.3 to assess the possible contributions of trends in winter precipitation and temperature to trends in SWE, we 

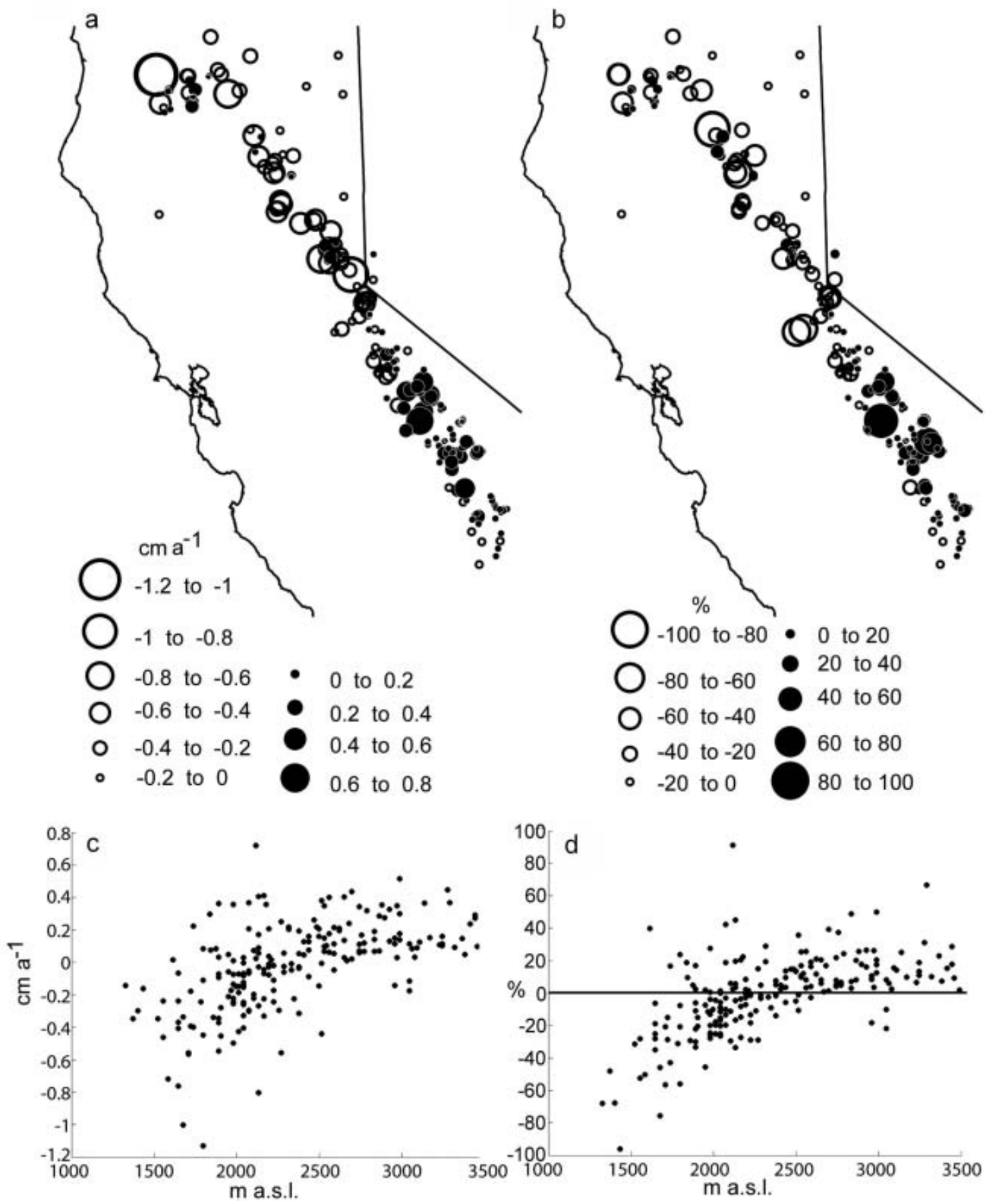

Fig. 2. (a) Map of linear trends in 1 April SWE for the period 1950-2002. (b) Relative change in SWE over 52 years as a percentage of the starting value ( $y$-intercept of the regression line). (c, d) SWE trend (c) and relative trend (d) plotted against station elevation.

find a distinct contrast between northern and southern halves of the study area (Fig. 3). The southern half of the Sierra Nevada presents a precipitation-dominated regime where trends in precipitation positively contribute, on average, $85 \%$ to trends in SWE. The highest elevations show a positive contribution of increasing temperatures to SWE trends, likely due to an increase in warmer, precipitationbearing storms. In the northern half of the state, increased temperatures dominate the contribution to decreasing SWE trends, accounting for nearly $100 \%$ of the total trend in the northern Sierra Nevada. The exceptions to this north-south contrast are in the corners and center of the study area. Both precipitation (positively) and temperature (negatively) contribute significantly to SWE in the northeastern high desert and mid-Sierra Nevada, the later marking the transition zone between the temperature- and precipitationdominated regimes discussed above.

Correlating trend in SWE with the spatial distribution of climate forcing, we find that trends in SWE have the greatest absolute magnitude where the contribution to the trend is dominated by either precipitation or temperature. Weak trends in SWE are found where increased precipitation and temperature have effectively offset each other, such as the northeastern high desert region and in the transition zone between the northern and southern Sierra Nevada. 


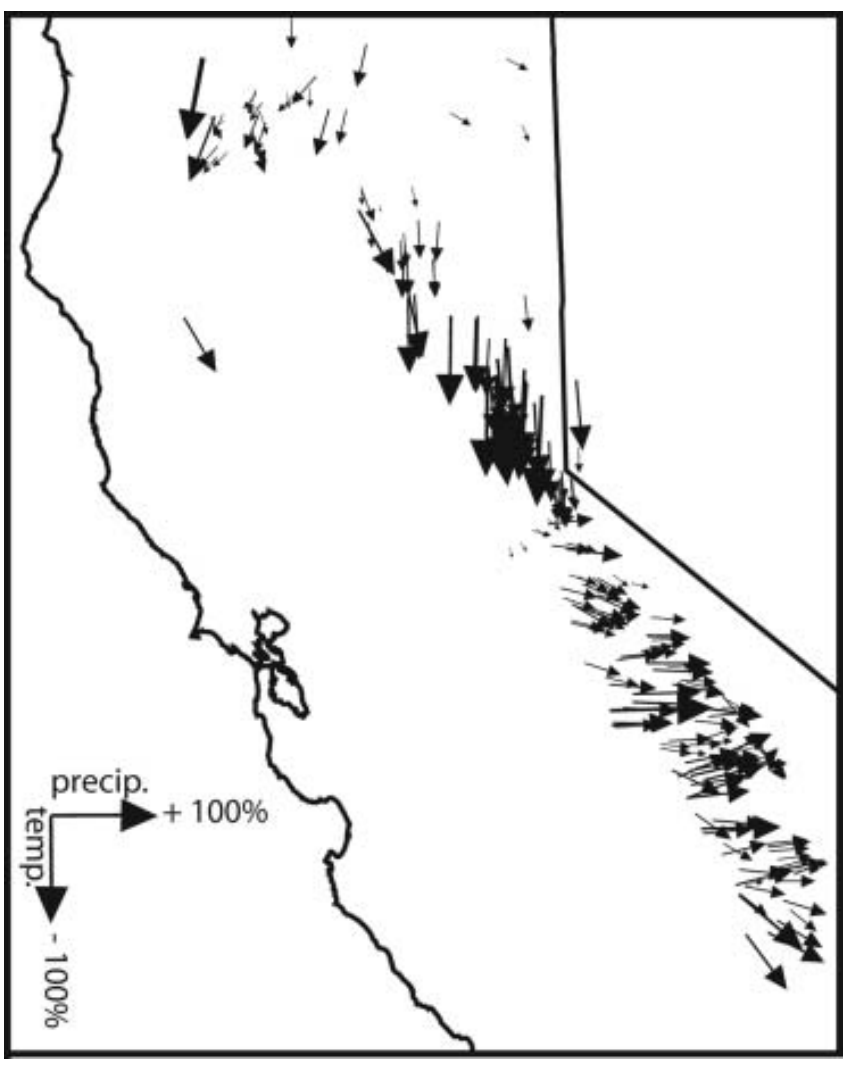

Fig. 3. Vector map of the contributions of trends in winter temperature (vertical axis) and precipitation (horizontal axis) to the trend in SWE for the period 1950-2002, expressed as a percentage of total SWE trend. A downward- or leftward-pointing arrow indicates a negative (anticorrelated) contribution of the climate trend to SWE trend. An upward- or right-pointing arrow indicates a positive contribution. Reference arrow lengths are 100\% of SWE trend.

\subsection{Correlation with Pacific climate indices}

In order to link the observed trends in California's SWE to global-scale climate, we determine the extent to which the observed trends in California's SWE can be explained by cyclical behavior of the Pacific Ocean. Previous studies have found a significant, but spatially variable, correlation between western United States spring SWE and both the Niño-3 index of the El Niño-Southern Oscillation (ENSO) and the PDO (Cayan and others, 1998; McCabe and Dettinger, 1999, 2002; Mote, 2003a).

The past half-century has been characterized by a switch from a negative to a positive phase of the PDO in the mid-1970s, corresponding to an anomalous strengthening of the Aleutian low and a resulting weakening and offshore shift of the Pacific winter storm track (Minobe, 1997). This regime has its largest effect on the climate of northern Pacific latitudes. In contrast, there have been several anomalously strong ENSO events in the past 20 years, which strengthen winter storms, resulting in more precipitation in California (Piechota and others, 1997). The contrasting influence of these two indices on California's climate can be seen in Figure 4. ENSO has a strong, positive correlation with SWE in both the north and south portions of the study area, and at mid- and high elevations. The PDO is only significantly $(p<0.05)$ anticorrelated to SWE at ten stations, all below $2000 \mathrm{~m}$ a.s.l. in the northern half of the study area.
Using the regression analysis outlined in section 2.3, we find that the observed trends in SWE can partially be attributed to shifts in these indices and their effects on temperature and precipitation. ENSO variability accounts for, on average, $32 \%$, and up to $77 \%$, of the trends in SWE while the PDO accounts for, on average, $28 \%$, and up to $80 \%$, of the trend. There is no clear spatial pattern in the contribution of ENSO to trends in SWE, as the contribution is equally positive at varying elevations and latitudes. The PDO, however, appears to have a stronger, negative, contribution to SWE at lower elevations and at higher latitudes $(r=0.62$ and -0.56 for correlations between the contribution of the PDO to SWE trend and elevation and latitude, respectively).

\section{DISCUSSION AND CONCLUSIONS}

The overall negative trend in SWE in California is consistent with observations of decreasing seasonal river discharges in major California watersheds (Dettinger and Cayan, 1995; Shelton and Fridirici, 1997; Knowles and Cayan, 2002). However, the overall rate of SWE loss is much less than that observed in the Pacific Northwest, where decreases have averaged $\sim 30 \%$ for the period 1950-2000 (Mote, 2003a). Such a contrast should not be completely unexpected, as previous researchers have found an anticorrelation between the climates of California and the Pacific Northwest, largely driven by the relative forcing of tropical and northern Pacific climate modes (Dettinger and Cayan, 1995; Cayan, 1996; Cayan and others, 1998).

California and the Pacific Northwest have experienced a relatively equal rise in winter temperatures over the past half-century. In California, however, unlike the Pacific Northwest, there has been a significant increase in highelevation SWE, partially offsetting the loss in low-elevation snowpack. The largest positive trends are in the southern Sierra Nevada, where there has been the greatest increase in winter temperature and precipitation in California. This gain in SWE during general climate warming may be attributed to an enhancement of wintertime orographic precipitation. This phenomenon, previously termed the 'snow gun effect' (Prentice and Matthews, 1991), is caused by orographic lifting of warmer, saturated air, above the freezing line, resulting in increased snowfall. In areas of especially steep, high topography, the enhancement of orographic precipitation can offset increased winter melt due to warming. Such appears to be the case in the southern Sierra Nevada and on Mount Shasta. The former presents the steepest gradient of the western side of the Sierras, and the latter lies directly within the winter Pacific storm track. The future efficacy of the 'snow gun' in offsetting increased melt is unknown, largely due to the coarse spatial resolution of regional climate models which are unable to simulate this finer-scale orographic effect (Cline and others, 1998; Kim, 2001). The importance of the snow gun effect in the overall SWE budget in California may have already found expression in the relatively small change in seasonal run-off despite snowpack loss at low elevations (Dettinger and Cayan, 1995).

Our analysis indicates that, in some cases, changes in SWE may be directly linked to the effects of ENSO and the PDO. The apparent increase in the frequency of positive ENSO winters over the past 50 years is correlated with increases in SWE at mid- and higher elevations throughout California. The low correlation between ENSO and 
a

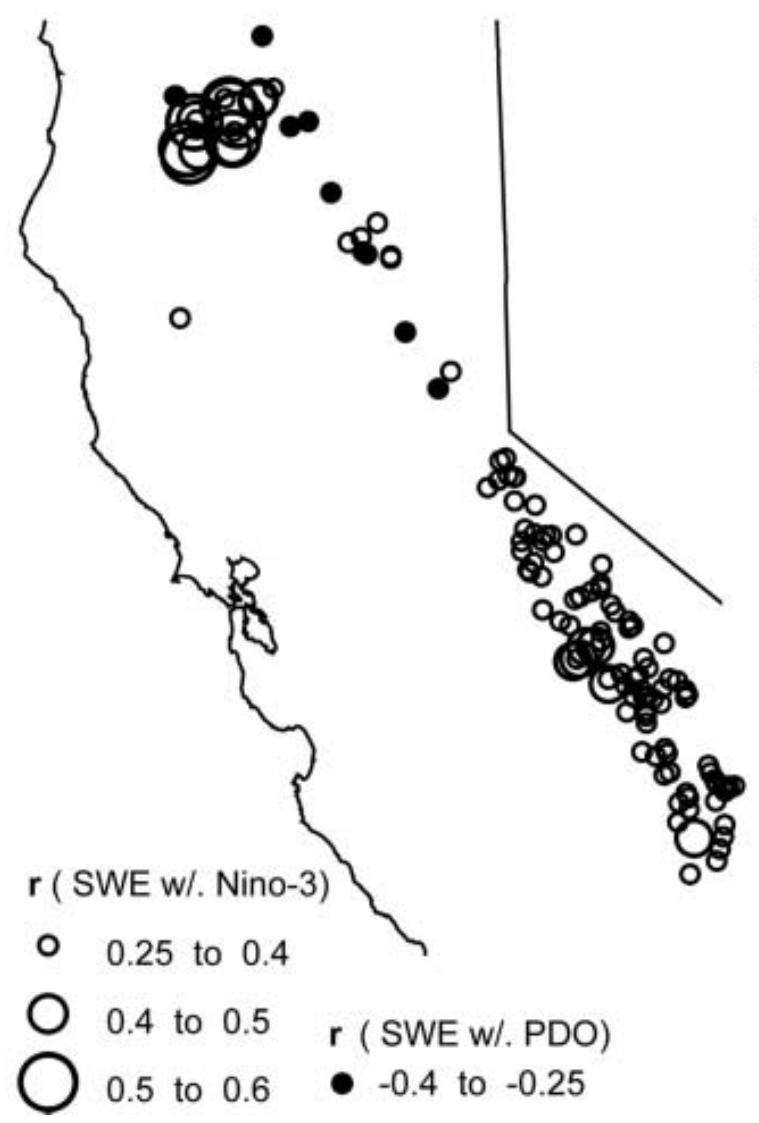

b

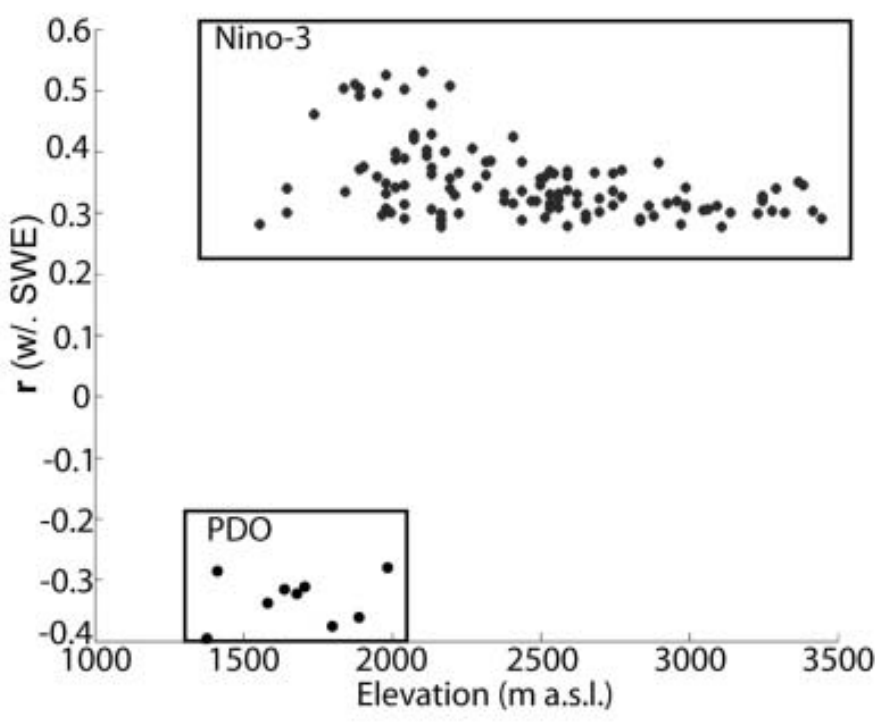

Fig. 4. (a) Map of correlation coefficient for 1 April SWE and the winter Niño-3 and PDO indices. Only correlations significant at the $p=0.05$ level are shown. (b) Significant $(p<0.05)$ correlations between SWE and Niño-3 and PDO indices vs elevation.

low-elevation SWE may be the result of the competing effects of higher temperatures and precipitation, as indicated by the correlation with regional climate in section 3.2. Conversely, drier winters associated with the PDO have served to decrease SWE in northern California. The effect of positive PDO phases is greatest at lower elevations, which are more sensitive to decreases in precipitation relative to temperature. However, these indices can only explain a portion of the observed trend in SWE for most of the study area. Therefore, other climatic and physiographic factors must be responsible for SWE trends.

\section{ACKNOWLEDGEMENTS}

This work was funded by grants from the University of California Center for Water Resources and the STEPS Institute. The authors thank M. Snyder, A. Nolin, L. Sloan and two anonymous reviewers for their help in improving the manuscript.

\section{REFERENCES}

Bohr, G.S. and E. Aguado. 2001. Use of April 1 SWE measurements as estimates of peak seasonal snowpack and total cold-season precipitation. Water Resour. Res., 37(1), 51-60.

Brown, R.D. 2000. Northern Hemisphere snow cover variability and change, 1915-97. J. Climate, 13(7), 2339-2355.

Cayan, D.R. 1996. Interannual climate variability and snowpack in the western United States. J. Climate, 9(5), 928-948.
Cayan, D.R., M.D. Dettinger, H.F. Diaz and N.E. Graham. 1998. Decadal variability of precipitation over western North America. J. Climate, 11(12), 3148-3166.

Cayan, D.R., S.A. Kammerdiemer, M.D. Dettinger, J.M. Caprio and D.H. Peterson. 2001. Changes in the onset of spring in the western United States. Bull. Am. Meteorol. Soc., 82(3), 399-415.

Cline, D., K. Elder and R. Bales. 1998. Scale effects in a distributed snow water equivalence and snowmelt model for mountain basins. Hydrol. Process., 12(10-11), 1527-1536.

Dettinger, M.D. and D.R. Cayan. 1995. Large-scale atmospheric forcing of recent trends toward early snowmelt runoff in California. J. Climate, 8(3), 606-623.

Groisman, P.Y., R.W. Knight and T.R. Karl. 2001. Heavy precipitation and high streamflow in the contiguous United States: trends in the twentieth century. Bull. Am. Meteorol. Soc., 82(2), 219-246.

Karl, T.R., C.N. Williams, Jr, F.T. Quinlan and T.A. Boden. 1990. United States Historical Climatology Network (USHCN) serial temperature and precipitation data. Oak Ridge, TN, Carbon Dioxide Information Analysis Centre..

Kim, J. 2001. A nested modeling study of elevation-dependent climate change signals in California induced by increased atmospheric $\mathrm{CO}_{2}$. Geophys. Res. Lett., 28(15), 2951-2954.

Knowles, N. and D.R. Cayan. 2002. Potential effects of global warming on the Sacramento/San Joaquin watershed and the San Francisco estuary. Geophys. Res. Lett., 29(18), 1891. (10.1029/ 2001GL014339.)

Lund, R.T., L. Seymour and K. Kafadar. 2001. Temperature trends in the United States. Environmetrics, 12(7), 673-690.

McCabe, G.J. and M.D. Dettinger. 1999. Decadal variations in the strength of ENSO teleconnections with precipitation in the western United States. Int. J. Climatol., 19, 1399-1410. 
McCabe, G.J. and M.D. Dettinger. 2002. Primary modes and predictability of year-to-year snowpack variations in the western United States from teleconnections with Pacific Ocean climate. J. Hydrometeorol., 3, 13-25.

Miller, N.L., K.E. Bashford and E. Strem. 2003. Potential impacts of climate change on California hydrology. J. Am. Water Resour. Assoc., 39(4), 771-784.

Minobe, S. 1997. A 50-70 year climatic oscillation over the North Pacific and North America. Geophys. Res. Lett., 24(6), 683-686.

Mote, P.W. 2003a. Trends in snow water equivalent in the Pacific Northwest and their climatic causes. Geophys. Res. Lett., 30(12), 1601.

Mote, P.W. 2003b. Trends in temperature and precipitation in the Pacific Northwest during the twentieth century. Northwest Science, 77(4), 271-282.
Piechota, T.C., J.A. Dracup, and R.G. Fovell, 1997. Western US streamflow and atmospheric circulation patterns during El Niño Southern Oscillation (ENSO). J. Hydrol., 201(1-4), 249-271.

Prentice, M.L. and R.K. Matthews. 1991. Tertiary ice-sheet dynamics: the snow gun hypothesis. J. Geophys. Res., 96(B4), 6811-6827.

Serreze, M.C., M.P. Clark, R.L. Armstrong, D.A. McGinnis and R.S. Pulwarty. 1999. Characteristics of the western United States snowpack from snowpack telemetry (SNOTEL) data. Water Resour. Res., 35(7), 2145-2160.

Shelton, M.L. and R.M. Fridirici. 1997. Decadal changes of inflow to the Sacramento San Joaquin delta, California. Phys. Geogr., 18(3), 215-231.

Snyder, M.A., J.L. Bell and L.C. Sloan. 2002. Climate responses to a doubling of atmospheric carbon dioxide for a climatically vulnerable region. Geophys. Res. Lett., 29(11), 4431-4156. 